\title{
Microcapsule-containing Self-Reporting Polymers
}

Céline Calvino, Christoph Weder*

C. Calvino, Prof. C. Weder

Adolphe Merkle Institute, University of Fribourg

Chemin des Verdiers 4, CH-1700, Fribourg, Switzerland

E-mail: christoph.weder@unifr.ch

This paper is dedicated to the memory of Prof. Scott R. White

Keywords: Microcapsules, mechanochromic, self-reporting polymers, damage sensing 


\begin{abstract}
Self-reporting polymers, which can indicate damage or exposure to excessive stress with a clearly perceptible optical signal, are potentially useful for several technological applications, including stress-sensitive sensors that enable in-situ monitoring of mechanical events and structural health monitoring systems. A versatile and simple concept to realize this function is the exploitation of microcapsules that are filled with solutions of dyes that are released and chemically or physically activated when the protective shell is damaged. Such microcapsules can readily be incorporated into polymers and the composites thus made can be processed into films, coatings, or other objects. Mechanochromic effects can be realized with different types of dyes and activation schemes. In this concept article, a selection of recent key studies is presented to provide an overview of the state of the field. Different architectures and operating principles and their advantages and drawbacks are reviewed. The parameters that influence the design of microcapsule-based mechanochromic systems are considered and unexplored chromophore systems that might be useful to design future self-reporting polymers are discussed. Finally, specific aspects of capsule design, fabrication, and integration into polymers are presented. Throughout the article, challenges and opportunities of the concept are highlighted and possible future directions are discussed.
\end{abstract}




\section{Introduction}

Mechanochromic polymers represent an emerging family of materials which possess the capability to alter their absorption and/or fluorescence characteristics upon application of mechanical force. ${ }^{[1]}$ The possibility to monitor mechanical stress and/or deformation at different length scales is of fundamental interest and a priori useful to study failure and stress transfer mechanisms. ${ }^{[2-4]}$ Mechanochromic transduction principles can also be exploited to create self-reporting polymers that indicate defects or the application of excessive stress with a clearly perceptible optical signal and which are potentially useful for technological applications such as tamper-evidencing packaging materials or stress-reporting sensors that facilitate the in-situ monitoring of mechanical events. Perhaps the most significant economic and societal impact of such materials could be in the context of structural health monitoring, ${ }^{[5]}$ notably in the aeronautic, ${ }^{[6]}$ automotive, ${ }^{[7,8]}$ and construction industries. ${ }^{[9,10]}$ Here, autonomously operating, mechanically responsive materials can offer enhanced reliability and safety vis-à-vis conventional polymers by revealing mechanical damage, wear, or ageing and indicate imminent mechanical failure of structural components via visual warning signs. In addition, maintenance schemes that currently rely on replacing or renovating structural components based on age or service time might in the future be based on the actual need for such changes, as indicated by the built-in monitors. Taking materials' autonomy to another level, there is a significant interest to pair such sensor functions with self-healing capability. ${ }^{[10]}$

Early efforts to devise mechanochromic polymers include the exploitation of conjugated building blocks with conformation-dependent absorption and dyes with morphologydependent absorption and/or emission characteristics. ${ }^{[1]}$ A more recent approach to realize mechanotransduction in polymers is the incorporation of so-called mechanophores. These motifs contain mechanically labile bonds that are reversibly or irreversibly cleaved upon mechanical activation and thereby convert mechanical forces into chemical reactions. ${ }^{[12-14]}$ 
Mechanochromic responses can be achieved if such reactions lead to optical changes, for example through the ring-opening reaction of spiropyrans. ${ }^{[15,16]}$ While the approach has been used to create a broad palette of mechanochromic polymers, the mechanophore must be covalently coupled with the macromolecules, so that significant synthetic efforts are required to use a given motif in different polymers. In addition, the mechanophore activation can usually also be triggered by heat ${ }^{[16]}$ or light ${ }^{[17]}$ which renders the responses unspecific. Finally, it appears that efficient stress transfer to the mechanophores is difficult (or even impossible) to realize in rigid polymers. The mechanically induced dispersion of aggregachromic chromophores embedded in polymeric matrices is an alternative approach to achieve mechanochromic responses. This framework has the advantage of not requiring the attachment of a specific motif to the polymer and thus extensive synthetic efforts for each new system, but the approach proved to be difficult to generalize. ${ }^{[18]}$ A versatile and conceptually simple alternative to realize mechanochromic responses in polymeric materials is the exploitation of microcapsules that are filled with a dye system that is released and chemically or physically activated when the capsule is damaged. ${ }^{[19,20]}$ Such microcapsules can a priori be readily incorporated in any polymer of interest by simple mixing and without any chemical modification, and mechanochromic effects can be realized with different types of dyes and activation schemes. The concept is reminiscent of the principle exploited in carbonless copy paper $^{[21]}$ and pressure-sensitive recording sheet ${ }^{[22]}$ technologies, where solutions of colorless dye precursors are released from microcapsules upon application of pressure and instantly react with a developer to form a highly colored dye. The concept did not attract much attention in the polymer community, until White and co-workers revisited the idea to release a cargo from breaking capsules to create autonomously self-healing polymer composites. ${ }^{[23]}$ In their pioneering study, the Illinois team incorporated microcapsules filled with a healing agent into a polymer matrix. The healing agent was released upon crack formation and polymerized upon contact with a catalyst embedded in the polymer. A red dye was co-encapsulated with 
the healing agent to visualize the release of the healing agent in the damaged region; however, as the dye featured the same optical properties within and outside of the capsules, the visual contrast achievable with this particular embodiment was limited. Nevertheless, the study kindled widespread research efforts on self-healing and healable polymers, the sensing of defects in polymers using capsule-release approaches, and combination of these concepts.

While research efforts on microcapsule-based self-healing polymers have witnessed a significant growth during the last 15 years, ${ }^{[24]}$ microcapsule-based materials with mere mechanochromic or self-reporting capability are, quite surprisingly, still limited. Nevertheless, by now there have been numerous reports that document the usefulness and significant potential of this concept to create self-reporting materials. ${ }^{[10]}$ The approach is strikingly simple and versatile in terms of activation modes and responses that can be achieved. Further, the use of microcapsules permits imparting new functionalities to a priori any polymeric material without the need of chemical modification, but instead, simple mixing of the active microcapsules with a polymer of interest. ${ }^{[25]}$ In this concept article, a selection of key studies is reviewed to provide an overview of the state of the research, illustrate the scope, and highlight the potential and challenges. In a first section, different architectures and operating principles are introduced and their respective advantages and drawbacks as well as the historical evolution and improvements are discussed. The physical and chemical parameters that influence the design of microcapsule-based mechanochromic systems are also addressed. Subsequent sections discuss unexplored chromophore systems that appear to be useful in the context of capsule-based self-reporting polymers, and specific aspects that relate to capsule design, fabrication, and integration into polymers. Throughout, challenges and opportunities of the concept are highlighted and possible future directions are discussed. 


\section{Architectures and operating principles}

The various architectures and general operating principles that have and can be used to create self-reporting polymers by the introduction of microcapsules filled with dyes or species taking part of a chromic system are illustrated in Figure 1. The figure illustrates three general approaches that have, in different variants, already been utilized to create release of the cargo to achieve self-reporting materials, as well as a hitherto unexplored fourth concept. The first approach involves the "simple" release of encapsulated, (optionally latent and/or fluorescent, dyes in the damaged region, which diffuse into and stain the matrix surrounding the broken capsules, in the case of latent dyes after interacting with the polymer or an agent contained in the latter. The second concept is based on the combination of two capsule types, containing the two components part of a chromic system. Their release from the capsules allows a physical or chemical interaction inducing a self-reporting response. The third concept implies the release of a cargo that changes its optical properties due to a physical transformation. A fourth, so far hypothetical, framework involves a double encapsulation scheme that involves the compartmentalized release of two interacting species within a protective shell.

\section{1. "Simple" release of an encapsulated dye}

The most basic approach to exploit microcapsules in self-reporting polymer systems involves the integration of dye-containing microcapsules into a polymer of choice, which simply release the dye upon rupture into in the surrounding polymer and color their immediate environment (Figure 1A). The formation of poly(urea-formaldehyde) (PUF) oil-in-water emulsions is the most common method to prepare transparent microcapsules with shell thicknesses of the order of a few nanometers and with average diameters in the range of tens to hundreds of $\mu \mathrm{m} .{ }^{[19],[26]}$ White's group employed this strategy by co-encapsulating a healing agent and a colored dye to visualize the release of the healing agent after damaging the materials. ${ }^{[23]}$ Others extended the approach to healing agents that were laced with fluorescent 
chromophores, or replaced the healing agent with low-volatility solvents and used fluorescent fluid-loaded microcapsules merely as crack-indicating agent. Upon mechanical damage of the host polymer the microcapsules rupture, release their fluorescent fluid cargo into the damaged region, and the redistribution of the fluorophore can be monitored under UV-light illumination. ${ }^{[27,28]}$ The main disadvantage of such simple release systems is that the dye displays the same optical properties inside and outside the microcapsules, which limits the contrast and, especially at high microcapsule content, makes a distinction between the intact and damaged material difficult. Credico and co-workers demonstrated that this problem can be overcome by equipping the microcapsules with a UV-light screening shell and employing a UV-sensitive photochromic dye (Figure 2). Dispersed in a poly(ethylene glycol methacrylate) photopolymer film, the dye-loaded capsules were indeed colorless, but once the capsules were damaged, the payload diffused into the matrix and revealed a clearly discernible color change upon UV illumination. ${ }^{[29]}$ A similar concept can also be applied to fluorescent probe molecules, for which no photochromic change is necessary. Postiglione et al. reported a microcapsule-based system in which a UV-light screening polyurea shell prevented the excitation of the fluorescent cargo in intact microcapsules, but upon rupture the released dye fluoresces brightly upon exposure with UV-light and yields an excellent contrast between locally damaged and intact regions of a polyurethane-based coating formulation that was used to demonstrate the usefulness of the capsule system in crack detection experiments. ${ }^{[30]}$

The latter systems document strikingly that on account of the simplicity of the strategy, its versatility with respect to the dye cargo, and its applicability to a large panel of matrix polymers, the "simple" release of an encapsulated dye is an approach that has significant merit. However, to achieve adequate contrast, such release must ideally be coupled with a mechanism that changes the optical properties (i.e., color or fluorescent color) of the dye upon release, ideally generating a high contrast between the "off" (intact) and "on" (damaged) state. 
As discussed above, such switching can be achieved by equipping the capsules with an "optical filter", or alternatively, mechanisms that change the properties of the sensor molecules upon release (Figure 1B). The various approaches that have been used to achieve this are summarized in the following.

\section{2. "Turn-on" mechanism based on cargo-matrix interactions}

An early example of a capsule-based system displaying a significant "turn-on" mechanism (Figure 1B) within a polymer was conceived by the groups of White, Sottos, and Moore, who embedded microcapsules containing the cyclic monomer 1,3,5,7-cyclooctatetraene (COT) in a poly(acrylic acid) matrix containing also the Grubbs-Love ruthenium metathesis catalyst

(Figure 3). ${ }^{[31]}$ The colorless conjugated cyclic olefin was employed as it is a precursor of the intensely colored poly(acetylene). Thus, when the composite was scratched, the monomer diffused into the matrix's damaged region and subsequently reacted with the dispersed catalyst, leading to an instant orange/red coloration of the originally colorless material and the sample eventually became purple, on account of poly(acetylene) formation. The authors offered the perspective that the color-generating, damage-indicating COT might be coencapsulated with another monomer, such as dicyclopentadiene, which would also be activated by Grubbs-Love catalyst and enable autonomous damage repair.

The chemical activation of an encapsulated "pro-dye" by a reagent or catalyst present in the matrix has subsequently attracted considerable attention and several materials based on this concept have been reported. For example, a mechanochromic response has been demonstrated by releasing colorless violet lactone leuco dyes into acid-containing acrylic resins. The $\mathrm{pH}$ variation incurred to the dye created a visible color change, from colorless to purple, allowing a visual detection of the material damages. ${ }^{[32]}$ 
Another possibility is to utilize a chemical indicator that does not require additional reagents (e.g., a color developer or a catalyst) or stimulation but which instead displays a color change upon interacting with the matrix polymer. Based on the working principle of carbonless copy paper, ${ }^{[33]} \mathrm{pH}$-sensitive dyes such as $2^{\prime}, 7^{\prime}$-dichlorofluorescein were encapsulated and dispersed into various amine-cured epoxy matrices. Mechanical damage in the form of incision, abrasion or compression released the payload into the matrix, where the interaction of the indicator with the residual amine groups led to a pronounced color change, from light yellow to bright red. ${ }^{[34]}$ Several other examples employing this general concept can be found in the literature. ${ }^{[35]}$ For example, thiols were released from either micro- or nanocapsules to selectively react with a rhodamine-based pro-fluorophore contained in a poly(methyl acrylate)

film, leading to a fluorescent turn-on effect. ${ }^{[36]}$ Perhaps the biggest disadvantage of relying on chemical reactions to elicit a chromogenic response lies in the questions how reliable such chemistries function over the lifetime of a material and to what extent these reactions are impacted by environmental effects. In addition, the ability to homogenously disperse a required "developer" in the matrix is highly dependent of the polymer, and strategies that rely on interactions with the polymer itself may not readily be broadly applicable to other host materials. As a result, researchers have recently shifted their attention to chromophore systems where physicochemical changes associated with the release from microcapsules trigger an optical change.

\subsection{Interactions of compounds released from two capsule types}

One of the first chemistry-free chromophore systems for capsule-based damage sensing was reported by the Weder group, which explored charge-transfer complexes as indicators for capsule-based damage sensing. Such complexes, which are formed upon assembly of an electron donating and an electron accepting species, are usually strongly colored, on account of an electronic charge transfer from the donor to the acceptor. ${ }^{[37]}$ Relying on a dual capsule 
approach (Figure 1C), toluene solutions of chloranil as an acceptor and hexamethylbenzene as a donor were independently encapsulated in PUF microcapsules and the two capsule types were embedded in a poly(dimethylsiloxane) matrix. This was accomplished by dispersing the capsules in the monomer before curing the composite. The application of mechanical forces in the form of stress, compression or incision caused the capsules to rupture, which led to the formation of a readily visible red charge-transfer complex. One may speculate (although this was not demonstrated in the original study) that the individual encapsulation of two components (as opposed to encapsulating only one and placing the second component simply in the matrix, as for the systems described in Section 2.2) may increase the fidelity of the mechanoresponse. False positive signals due to unspecific cargo release from the capsules may be reduced, if two different capsule types are required to break. The strategy offers the possibility of tuning the color change via the choice of the donor-acceptor pair, and the twocapsule type approach can also be exploited with other interacting (pro)dye types, including fluorophore/quencher or fluorophore pairs displaying energy transfer, upconverting dye pairs, as well as the chemically reactive systems discussed above. Indeed, a "click" reaction generating a fluorogenic response was demonstrated for a dual capsule system in which azides and alkynes were released from poly(vinyl-formal) capsules into an epoxy matrix. ${ }^{[38]}$

\subsection{Aggregation-Induced Optical Changes upon Dye Release}

Another possibility to achieve chemistry-free optical changes is the encapsulation of chromophores that change their optical properties on account of the physical changes to their immediate environment upon release from a microcapsule (Figure 1D). Luminogens that display an aggregation-induced emission (AIE) turn-on represent one class of sensor molecules explored in this context. These molecules, which have lately attracted much attention, do not exhibit any strong fluorescence when dissolved in a good solvent, on account of vibrational and/or rotational modes that promote non-radiative relaxation pathways for 
electronically excited states. ${ }^{[39]}$ Aggregation restricts such intramolecular motions so that the emission is turned on or (if not completely suppressed in solution) vastly enhanced. Exploiting this effect, Robb et al. encapsulated a hexylacetate solution of the widely used AIE luminogen 1,1,2,2-tetraphenylethylene in PUF microcapsules, which were embedded into a variety of polymer matrices, including a polyurethane, poly(acrylic acid), poly(styrene), and a UV-cured epoxy resin (Figure 4). As intended, the pristine microcapsules, and also the intact polymers containing the latter, are colorless and display no fluorescence. However, bright blue fluorescence was observed within minutes after inflicting damage to the neat capsules or the polymer composites, on account of triggering aggregation-induced emission upon releasing the dye from the capsules driven by the solvent evaporation. ${ }^{40]}$

We recently reported a similar approach which involved fluorescent dyes that display aggregation-induced excimer-formation (Figure 5). Building on previous studies that involved excimer-forming and aggregachromic fluorescent cyano-substituted oligo(phenylene vinylene) derivatives (cyano-OPVs $)^{[18,41,42]}$ we selected 1,4-bis( $\alpha$-cyano-4-(2-ethylhexyloxystyryl))-2,5-dimethoxybenzene (BCEDB) ${ }^{[43]}$ for initial studies, as the emission maxima of solutions and solid powders of this dye differ considerably, both forms are highly fluorescent, and the two ethylhexyloxy groups render the dye highly soluble in organic solvents. Thus, PUF microcapsules filled with a BCEDB hexylacetate solution display bright green fluorescence, whereas damaging the capsules led to a pronounced change of the fluorescence color from green to orange, on account of solvent evaporation, aggregation, and excimer formation. A similar response was observed when the microcapsules were embedded in a silicone rubber and the materials thus made were subjected to mechanical impact, incision, compression, or tensile deformation. One key advantage of using excimer-forming chromophores is that the response is a mechanically induced change of the fluorescence color, rather than a turn-on or turn-off effect, which renders the signal ratiometric. This in turn 
permits, in contrast to other schemes, a straightforward quantitative assessment. Posterior color analysis of photographs can be employed to monitor the mechanochromic response of this system enabling the quantification of the prior mechanical energy applied to the material. ${ }^{[44]}$ It appears also feasible to extend the approach to "aggregachromic" compounds, i.e., dyes that change their optical absorption characteristics upon self-assembly, either due to conformational changes or on account of charge-transfer interactions. In this case, a readily detectable a color change should be observable.

\subsection{Other Architectures}

Several possibilities exist to further broaden the palette of architectures that can be exploited in the context of self-reporting capsule systems. For example, double-walled microcapsules (i.e. capsules within capsules) represent an un-explored architecture that could offer attractive features (Figure 1E). The approach would require an inner capsule with an easily breakable shell and a host capsule with a more elastic wall so that upon compression, the elastic container would deform and translate forces to the inner capsule, inducing its rupture, while the protective shell would remain intact. Chromogenic responses can be achieved by several of the mechanisms discussed before and separately encapsulating two components that are able to generate a colorimetric response upon interaction in the inner and outer capsules. The design should offer more predictable interactions in a more localized position and the mechanism is independent of the environment, i.e., the polymer matrix, rendering the system truly universal.

Microcapsules are not the only reservoir type suitable for the preparation of damage selfreporting materials. Indeed, several other reservoir systems have been shown to be useful in this context. For example, hollow fibers have been explored as dye containers which could be ruptured in polymer matrices releasing their contents upon mechanical damage. This approach 
has extensively been explored in connection with self-healing materials in which healing agents and indicator dyes served both to fill the hollow fiber and repair the matrix. ${ }^{[45,46]}$ Vascular networks made of interconnected micro-channels have also been used to visualize the release of healing agents into the damaged region of the materials. Finally, first capsule systems with dimensions on the nanoscale have been employed for similar purposes. ${ }^{[47]}$ Reducing the size of the microcapsules is important for the fabrication of thin coatings in which the thickness is only a few or a few tens of $\mu \mathrm{m}$.

\section{Useful Chromophore Systems}

It is evident from the examples presented in Section 2 that a broad range of dye systems and operating principle can be exploited to create microcapsule-based self-reporting polymers. As previously discussed, such chromogenic systems could rely on the chemical reaction of two components either, one encapsulated and the other embedded in or part of the matrix or both individually encapsulated and reacting through their release within the matrix. Physical changes such as aggregation induced emission, excimer formation, or aggregachromic effects have also shown to be attractive for implementing a turn-on effect or a (fluorescence) color change, which in certain cases can gave access to ratiometric assessments. It appears that many other interesting design approaches are still waiting to be explored. With respect to practical usefulness, a pronounced absorption color change that can be detected without auxiliary means, or a significant fluorescence color change, which affords a ratiometric selfreferencing signal appear preferable over "turn-on" or "turn-off" effects where the read-out not only depends on the actual change, but also the measurement conditions, such as distance from a sample, depth of a defect, etc. However, many systems could be modified into selfcalibrating features by adding a reference fluorophore / chromophore whose optical characteristics do not change and which can serve as internal standard. 
Various mechanisms based on charge or proton transfer between molecular species are known to cause fluorescence or UV-visible properties changes and could be of great interest to create microcapsule-based self-reporting polymers. ${ }^{[48-50]}$ For example, Förster resonance energy transfer (FRET) and electronic energy transfer (EET) between two emissive chromophores or an emitter and a quencher and in a similar manner photo-induced electron transfer (PET) involving an excited electron which is transferred from a donor to and acceptor can be used to induce fluorescence color changes as well as fluorescence turn-off. Moreover, an off-on fluorescence switching can also be achieved by the use of fluorophore-spacer-receptor constructs. ${ }^{[51,52]}$ For example, the coordination of azobenzene-rhodamine derivative dyads and $\mathrm{Al}^{3+}$ ions, was found to generate a fluorescence turn-on via a FRET process. In this system, the coordination induces a spirocyclic ring opening of the molecule, which in turn promotes FRET from the azobenzene moiety (donor) to the rhodamine (acceptor). ${ }^{[53]}$ Another example was reported by Gunnlaugsson, who used an anthracene-based fluorescent PET sensor carrying thiourea moieties as binding sites. Upon coordination to a wide range of anions, such as acetates, phosphonates, fluorides the PET fluorescence is quenched, inducing a turn-off effect. ${ }^{[54]}$ Similarly, intramolecular charge transfer (ICT) between a donor moiety and a chromophore-spacer-receptor can be employed to generate different ranges of visual color changes. ${ }^{[55]}$ For example, thiosemicarbazide-naphthalimide-based chromophores and amines can be employed as chromogenic complex, which upon deprotonation generates a red-shift absorption via internal charge transfer with a concomitant visual color change from yellow to purple. ${ }^{[56]}$ Excited-state intramolecular proton transfer (ESIPT) is a fluorescent phenomenon that involves photo-excited molecules relaxing their energy through tautomerization by proton transfer. ${ }^{[57]}$ Usually switched on or off by an analyte, such molecules may also be attractive for self-reporting features. One example involves the 2-(2-hydroxyphenyl)-benzothiazole (HBT)-rhodamine dyad, which upon interaction with tetrafluoroacetic acid switches off its yellow ESIPT emission at $579 \mathrm{~nm}$; the process is reversible and the luminescence can be 
restoredthrough the addition of a suitable base, e.g., triethylamine. ${ }^{[58]}$ The ESIPT effect can also be induced or suppressed by molecular aggregation, and therefore be employed to achieve AIE or aggregation induced excimer formation. ${ }^{[59]}$ In addition, ESIPT chromophores were also shown to display aggregation-induced enhanced emission (AIEE) ${ }^{[60]}$ or restriction of intramolecular rotation (RIR) and therewith environment-dependent fluorescence characteristics. ${ }^{[59]}$ Molecules that display solvatochromic absorption or emission characteristics can also exhibit pronounced (fluorescence) color changes upon being transferred from a nonpolar solvent into a polar polymer matrix (or vice versa) and appear useful in the context of self-reporting systems. ${ }^{[61,62]}$ For example Giordano et al. developed fluorescent solvatochromic 7-aryl-3-hydroxychromones chromophores which exhibit four different emission colors when dissolved in heptane, toluene, THF or DMSO, resulting in a shift of the emission band by as much as $174 \mathrm{~nm} \cdot{ }^{[63]}$ Finally, the optical properties of many metal complexes depend on the coordination sphere, and can readily be changed by a simple ligand exchange. ${ }^{[64]}$

The exploitation of molecular logic gates involving the aforementioned fluorescent phenomena seems to be another possible path towards self-reporting materials. Various examples of advanced molecular switches that combine two or three different mechanism (e.g. ICT-FRET or PET on-off-on) that sense different analytes have been reported. ${ }^{[65]}$ Thus, their implementation into encapsulated system should allow one to create complex systems with dual or multiple fluorescence response. Akkaya's group reported a monostyryl-BODIPY chemosensor carrying dithioazacrown and dipicolylamine ligands that combine PET and ICT mechanisms. While the original emission of the chromophore is centered around $679 \mathrm{~nm}$, the selective coordination of $\mathrm{Hg}^{2+}$ induces a blue shift to $570 \mathrm{~nm}$ via ICT, resulting in a change of the fluorescence color to yellow. When both $\mathrm{Hg}^{2+}$ and $\mathrm{Zn}^{2+}$ are coordinated to the chromophore both PET and ICT effects are suppressed, resulting in a drastic increase of the 
fluorescence intensity and a change to bright orange-colored emission. Thus, these types of systems are suitable for the design of chromic logic gates. ${ }^{[66]}$

Optical upconversion, which relies on triplet energy transfer from a sensitizer (typically a metal complex) to an emitter and subsequent annihilation of two emitter triplets under formation of an emissive singlet excited state is another possibility to generate a fluorescence change, causing light emission at lower wavelength when both compounds interact. ${ }^{[67,68]}$ For example, the well-known sensitizer/emitter pair palladium octaethylporphyrin (PdOEP) and 9,10-diphenylanthracene (DPA) could be used to switch from red PdOEP phosphorescence to blue DPA fluorescence upon releasing the two individually encapsulated chromophores into a rubbery polymer matrix. ${ }^{[69]}$

The above-discussed chromophores, which are meant to serve as examples for their respective families, appear all readily be applicable in dual microcapsule-based systems, by encapsulating each component separately and allowing their association and interaction upon breakage of the microcapsules. Another way to exploit these systems could be the encapsulation of only one of the two components and the dispersion of the other one into the matrix. Finally, many of the mechanisms summarized here can further be combined with chemical reaction or interaction schemes.

In addition to the investigation of different chromic systems, the development of new characterization techniques is of great interest to expand the capabilities of the approach. Recently, Sottos and co-workers reported the first photoacoustic damage reporting probe, combining photoacoustic (PA) imaging with $\mathrm{pH}-$ responsive dyes to generate a turn-on PA signal. ${ }^{[70]}$ Once released into an amine-based epoxy matrix, the dye is deprotonated which causes an absorption shift to a state that is characterized by a large extinction coefficient and thus able to generate a PA signal in the damaged region. Importantly, PA imaging offers damage 
detection within a material and thus overcomes the fundamental limitation of optical techniques that are typically only applicable to the detection of damages on or near the surface.

\section{From capsules to self-reporting composite materials}

\subsection{Encapsulation and capsules}

Microencapsulated products are extensively used in food packaging, as well as in medical, industrial, and agricultural sectors. ${ }^{[71]}$ Consequently, a variety of encapsulation techniques have been developed providing microcapsules that vary in shell and core material types, size and size distribution, permeability, and mechanical integrity. The choice of the encapsulation technique depends on the desired architecture, notably the microcapsule dimensions as well as shell and core types, which in turn have to support the release mechanism at play. Table $1^{\text {[71] }}$ summarizes the different microencapsulation methods, typical shell materials, and their traditional application areas.

Obviously, the microcapsules used for the preparation of self-reporting materials must be sufficiently robust to remain intact during the processing of composites with a host polymer, and only rupture after the application of force. In addition, a long-shelf life of the capsules is required and thus leakage and diffusion of the encapsulated core, especially the solvent, must be prevented over a significant time period. So far, microencapsulation by interfacial polymerization has been the most commonly used approach for the preparation of microcapsules for self-reporting materials, on account of the simplicity of the process, and the low cost and scalability of the method. The most widely used embodiments encompass the oil-in-water emulsion polycondensation of amines with aldehydes, acid chlorides, or isocyanates, ${ }^{[72]}$ and also of urea-formaldehyde (UF), ${ }^{[73]}$ polyurethane-formaldehyde (PUF), ${ }^{[74]}$ melamine-formaldehyde (MF), ${ }^{[75]}$ melamine-ureaformaldehyde (PUMF), ${ }^{[76]}$ and melamineacrylate, ${ }^{[77]}$ where the polymer shell wall is formed at the interface between the normally 
hydrophobic droplets and the aqueous continuous phase. During this process, a vigorous agitation emulsified the lipophilic dye solution in the aqueous phase generating small droplets constituting the core of the emerging capsules. Once the reaction is initiated, the polymerization takes place at the water/organic solvent interface and slowly forms the capsule wall. The majority of microcapsules used for self-reporting materials were made using this simple preparation technique. The containers produced feature useful mechanical characteristics, the nature of the liquid core can readily be varied, and a broad range of sensor molecules can easily be integrated. Self-reporting materials demand certain capsule characteristics, and it appears that in-situ polymerization techniques are well suited for their preparation. Nevertheless, a range of techniques remain at researchers' disposal, and may be more appropriate if a specific shell material, size or different core is targeted.

\subsection{Capsules properties: distribution, size, stability}

In interfacial polymerization encapsulation techniques, the microcapsule size can be controlled in a range of 0.5 and $1100 \mu \mathrm{m}$ by adjusting the agitation rate during the encapsulation process. ${ }^{[78]}$ For example, Brown et al. demonstrated a linear correlation between average diameter and agitation speed for microcapsules prepared by in-situ polymerization and showed that it is possible to robustly produce capsules with diameters ranging from 10 to $1000 \mu \mathrm{m}$ controlling an agitation rate between $200-2000 \mathrm{rpm}$. The increase of the agitation rate reduces the droplet size of the emulsion and thereby decreases the average diameter of the capsules and provides a rather narrow size distribution, although high-shear conditions cause fracture of the microcapsules and lead to low yields. ${ }^{[26]}$ By contrast, lower agitation speeds lead to an increase of the microcapsule size and also a broader size distribution, as illustrated in Figure 6A. 
The microcapsule size plays an important role in the mechanically triggered release behavior. Investigations on the delivery of a healing agent demonstrated that capsules with larger diameters led to a more efficient release. ${ }^{[79]}$ White and co-workers established a relationship between microcapsule size and weight fraction, and crack volume and found that a decrease of the capsules' size does not necessarily requires an increase of the capsule content in the polymer to ensure efficient self-healing. Based on these findings, the group rationally designed self-healing systems that were tailored to repair specific types of damage. ${ }^{[80]}$ It stands to reason that developing in a similar manner a fundamental understanding of the relationship between the microcapsules dimensions and the color response of self-reporting materials would be useful to rationally design such systems. A priori, one would suspect that large capsules (which upon one rupture event release a more significant amount of dye than smaller ones) have the ability to elicit more pronounced signals, whereas the spatial resolution could be improved by using smaller containers.

Another important parameter is the shell thickness, which dictates the mechanical robustness of the microcapsules, as well as the permeability of the wall. In interfacial polymerization encapsulation techniques, the shell thickness can be controlled via the monomer to core ratio, processing parameters such as emulsifier concentration and temperature, but also irregularities during the mixing process or contaminated glassware, can also slightly affect the thickness of the shell. ${ }^{[81]}$ Yadav et al. showed that the crystallinity of the polymer can also influence the shell thickness and permeability. ${ }^{[82]}$ The shell thickness and the capsule diameter are not $\grave{a}$ priori related. However, it has been demonstrated that the distribution of shell thickness seems to increase with the dimensions of the capsules rendering the production of tailored microcapsules difficult. ${ }^{[83]}$ Given these limitations and the fact that one important application of self-reporting polymers is in coatings, which typically feature a thickness in the range of a 
few to a few tens of $\mu \mathrm{m}$, more research towards reducing the size of reporter microcapsules appears to be indicated.

Besides the techniques mentioned above, among the different possible encapsulation techniques (Table 1), microfluidics devices have become an attractive device for the preparation of microcapsules. This powerful technology is currently in its emergence for a variety of applications as it benefits from providing rapid mass delivery, the use of reduced amounts of reagents together with low waste generation. ${ }^{[84]}$ Microfluidic microcapsule fabrication is based on a double emulsion process in which a first fluid is jetted into an immiscible second fluid, which is subsequently surrounded by a third fluid. The capsules are then formed by the polymerization of monomers contained in the intermediate phase (second fluid). A precise control of fluid flow permits the preparation of well-defined capsule shape, diameter and a reproducible shell thickness. All these properties can be modulated by the geometry of the microfluidics devices and the flow rates, as well as the types of fluids. This allows high encapsulation efficiencies and makes this method more robust than other microcapsule production techniques. Indeed, the modulation of the previously mentioned parameters could permit the generation of a variety of microcapsules with highly defined resistance to mechanical damage. Thus, these types of microcapsules could yield the formation of materials with very predictable mechanochromic properties. Similarly to the systems made by interfacial polymerization, microfluidics can also provide monodisperse microcapsules $(\sim 60 \mu \mathrm{m})$ with hydrophobic core and thin shell thickness (less than $1 \mu \mathrm{m}$ ) using water-in-oil-in-water $(\mathrm{W} / \mathrm{O} / \mathrm{W}) \cdot{ }^{[85]}$ More detailed investigations on capsule mechanics were reported on capsules made by an oil-in-water-in-oil process. For example, Studart et al. tuned the shell thickness, size, permeability, mechanical characteristics, and chemical structure of monodisperse microcapsules using microfluidics. ${ }^{[86]}$ The group further predicted the mechanical properties of acrylate-based microcapsules differing in size and shell thickness 
under compression using fitting models. The study demonstrated that the force to break increases with both, the shell thickness and the diameter of the capsules. ${ }^{[87]}$ Thus, it appears feasible to use the technique to independently control shell thickness and capsule size to dialin a desired rupture force.

Microfluidic processes appear to be well-suited to prepare the above-mentioned dual-capsule systems, as demonstrated by work of Chu et al., who employed a $\mathrm{O}_{1} / \mathrm{W}_{2} / \mathrm{O}_{3} / \mathrm{W}_{4} / \mathrm{O}_{5}$ (with $\mathrm{O}=$ oil, $\mathrm{w}=$ water phase) quadruple emulsion for the one-step preparation of so-called Trojanhorse-like stimuli-responsive microcapsules. This technique allows the production of capsules with different shell materials and thus different functionalities. The group demonstrated the usefulness of such capsule systems for the controlled release of the payloads stored in the different compartments. In addition, adjustments of the flow rates permitted a tuning of size, shell thickness and content amount for an optimized release profile. ${ }^{[88]}$

\subsection{Liquid core and stability}

Microcapsules used for damage indication applications must impermeably enclose the core material, protect it from the external environment and remain stable for an extended period of time before eventually delivering the cargo. Preventing the loss of the cargo before any mechanically induced damage during processing, storage, or service is important to avoid any false responses and ensure functionality over time. Elevated processing temperatures, high shear conditions, and exposure to inadequate chemicals or solvents can induce the degradation of the microcapsule shell or result in the diffusion of the core material through the wall and into the host matrix and could cause a premature color change producing a false positive response. Indeed, such effects were shown to impact the function of capsule-based selfhealing polymer systems. ${ }^{[89,90]}$ 
The double-walled shell morphology of PUF-based microcapsules made of a smooth internal membrane that is free of pores and inclusions and a rough porous outer surface (Figure 6B) have been shown to provide improved long-term isolation at room temperature when compared to their analogous UF containers and such capsules were further shown to be highly stable at elevated temperature. ${ }^{[91]}$ Other techniques such as the incorporation of doublelayer microcapsules or protective surface coatings were employed to further improve the stability of the microcapsules. ${ }^{[92]}$

In order to maximize the shelf-life time, the solvent used for the core should ideally be of low volatility and ideally also not or only minimally alter the mechanical properties of the surrounding matrix once released. Examples of core materials used in other applications include migrin oil, ovalbumin, n-octadecane, n-hexadecane, n-eicosane, and butylstearate, all encapsulated in a polyurea shell, ${ }^{[93]}$ and a palm oil based alkyd ${ }^{[94,95]}$ incorporated in a PUF shell. In the context of self-reporting materials, Credico et al. used sunflower oil as core material to release UV-responsive chromophores from UV-protective shells. ${ }^{[29]}$ In this approach, and similarly as for charge transfer formation or interaction with a component present in the matrix, the faith of the solvent is of lesser importance. By contrast, several of the approaches that can be harnessed to create mechanochromic responses, including the aggregation-based dyes presented in Sections 2.2 and 2.4 and some of the chromophore systems suggested in Section 3, require or benefit from the evaporation of the solvent. Thus, the question arises to what extent adequate compromises between long shelf-life and rapid chromic response are possible. Our own investigations showed that shelf life of months is possible with a chromic response occurring in minutes range but even more efficiently, commercial systems such as carbonless copy paper or pressure indicators seem to have completely solved this issue. Two-capsule systems comprising different low-volatility cores represent a promising approach to improve both, the long-term stability as well as the res- 
ponse time upon release, as the response would rely on mixing, rather than evaporation. This solution appears to be applicable to dyes that display optical changes upon aggregation, as well as chromophores ${ }^{[96]}$ or nanoparticles ${ }^{[97]}$ with concentration-dependent optical properties.

\subsection{Composite fabrication}

Different techniques can be employed to disperse the capsules into a polymer matrix and produce films or coatings, which represent the most accessible and useful product shapes in which self-assessing behavior can be harnessed. For example, the capsules can be mixed with a monomer or a mixture of monomers which are then cast and cured. Alternatively, the polymer is dissolved or dispersed in a minimum amount of a solvent that does neither swell, nor dissolve the capsule material, the capsules are added, and the composite material is cast and solidified by evaporation of the solvent. If mixtures of low-viscosity are processed, it is possible that the microcapsules sediment and generate inhomogeneous dispersions. This problem can be solved by adjusting the viscosity of the mixture and/or maximizing the volume fraction of the capsules. However, the incorporation of large amounts of microcapsules into polymer matrices can affect the mechanical properties of the system. ${ }^{[37],[98]}$ Typical self-reporting materials described in the literature thus contain $10-20 \mathrm{wt} \%$ of microcapsules. A widely employed technique in the nanocomposite field is to graft polymer chains to or from the surface of the (nano)filler particles to promote their dispersion in and interactions with the polymer host. This strategy might also be useful in the context of the present microcapsule approaches. Beyond helping with dispersion, the entanglements of the grafted polymer chains with the surrounding matrix might directly have an impact on the force transduction to the capsules and might facilitate their rupture. To our best knowledge, however, such modifications have yet to be explored. 
Melt-processing is another straightforward option that remains so far unexplored in the context of capsule-based self-assessing polymers. Indeed this approach would offer great advantages for the production of self-assessing films, as sedimentation of the capsules could be avoided, problems associated with the use of a solvent could be circumvented, and processed could readily be scaled up. However, it is not clear to what extent the elevated temperature necessary to melt the host polymers might be damaging the capsules.

\subsection{Stress-transfer in capsule-containing composites}

Many techniques have been developed to characterize the mechanics of microcapsules, such as optical, magnetic and electromagnetic tweezers, micropipette aspiration, shear flow experiments, and force spectroscopy experiments, which in connection with appropriate theoretical models provide detailed information on the deformation properties of individual capsules. ${ }^{[99]}$ Keller and Sottos used single capsule compression tests to investigate the elastic modulus and failure behavior of PUF microcapsules of different diameters. ${ }^{[100]}$ The study revealed similar Young's moduli for PUF capsules of three different diameters $(213,187.65$ $\mu \mathrm{m})$. However, the capsules size had an effect on the burst behavior, with lower loads burst for smaller capsules. Zhang et al. employed a micromanipulation technique to measure the bursting force required to rupture or deform single microcapsules made with three different shell materials, including MF, UF, and gelatin-gum arabic coacervate, revealing that the mechanical strength increased. More specifically, MF and UF capsules revealed plastic deformations beyond their yield points at 19 and 17\% respectively, and a burst deformation at $68 \%$ and $35 \%$, while gelatin based microcapsules exhibited an elastic behavior without burst. Finally, bursting forces and deformations required for MF and UF capsules appeared to proportionally increase with the capsules diameters. ${ }^{[101]}$ These findings reveal that the rupture force can easily be tailored over a wide range (which can be broadened by using other shells and methods), which in turn should allow one to design composites with the same host 
polymer in which the capsules are activated at different load/deformation levels. Accordingly, it should also be possible to create force-responsive system composed of multiple capsules with different shell materials and/or thickness, which would rupture upon application different forces. Combined with appropriate colorimetric systems, this approach would allow the preparation of visual and quantitative gradient force responsive material.

While many studies have focused on the investigation of single microcapsule mechanics, much less attention was paid to the deformation and rupture of microcapsules incorporated in polymeric materials. Indeed, the primary goal of most studies was to qualitatively detect damages such as deliberately applied scratches. ${ }^{[29],[40],[102]}$ It stands to reason that in such experiments, which often involve cuts made with a sharp, rigid tool, the majority of capsules are directly damaged and opened by the tool. By contrast, only few reports have shown that the embedded microcapsules can liberate their content upon mere tensile deformation or compression of the matrix. ${ }^{[37],[44],[103]}$ Experiments have revealed capsule rupture at low strains $(1.5 \%)$ in low-modulus matrices such as poly(dimethylsiloxane), but little is known about the stress transfer from the polymer to the capsules and how the chromogenic responses caused by their rupture can be related to the mechanics of the matrix material. It is clear that more systematic studies are needed to develop a better understanding for the parameters that matter and to enable a quantitative correlation of mechanochromic response with matrix polymer mechanics.

\subsection{Potential applications of self-reporting microcapsule based systems}

Chemical degradation, fatigue, or mechanical impact are common elements that eventually lead to mechanical failure of polymer objects, often after the initial formation of micro-scale damages. ${ }^{[104]}$ Thus, the early assessment of (the onset of) mechanical damage is helpful to prevent eventual catastrophic failure, and enhance the materials' reliability and possibly 
service time. The self-reporting microcapsule systems discussed in this article appear useful in different ways, ranging from self-reporting strategies to self-healing approaches in which damages to a surface are not only signaled but also instantaneously repaired. ${ }^{[105]}$

The most straightforward, useful, and most-widely addressed application form of selfreporting microcapsules is in coatings, ${ }^{[106]}$ where damages allow chemicals to penetrate the protective layer and cause corrosion of the underlying substrate. Indeed, there are many papers in which the development of capsule-based sensor systems is motivated by the goal to impart coatings and paints with mechanical damage sensing. For example, Sottos and coworkers reported epoxy coatings embedded with self-reporting microcapsules generating a color change from light yellow to red upon mechanical damage and show a stability over 8 months. ${ }^{[34]}$ In another example, Bannwarth et al. developed self-reporting coatings using nanocapsules that contained a solution of a latent dye within the core and which were coated with a developer. Upon mechanical damage, the dye is released and developed upon contact with the developer, leading to a pronounced coloration of the damaged area. This strategy was reported to be useful for the detection of micro-cracks and, in connection with a healing agent that also reversed the coloration of the dye, also to monitor the healing of coatings. ${ }^{[47]}$ Perhaps the most important potential application of such coatings is the structural health monitoring ${ }^{[5]}$ in aerospace, ${ }^{[6][107]}$ automotive, ${ }^{[7,8]}$ construction ${ }^{[9,10]}$ and other industries, where mechanochromic materials can offer enhanced reliability by revealing mechanical damage, wear, or ageing and indicate imminent mechanical failure of structural components via visual warning signs. For example, Song et al. reported that it is possible to probe microcracks in cementitious materials by employing a coating that comprises microcapsules loaded with a fluorescent dye. ${ }^{[28]}$ As microcracks can limit the mechanical properties and thus load carrying capability of a material (whether ceramic, metallic, or polymeric) and propagate and/or lead to larger 
defects, it is essential to detect such defects in the initial stage, so that repair or replacement can be carried out before failure occurs.

Self-reporting microcapsules can also be embedded in bulk materials, but unless the material is transparent, thin, or specific techniques are used that permit to "look beyond the surface", ${ }^{[70]}$ sensing remains limited to surface effects. It is also possible to create selfreporting fibers, ${ }^{[108]}$ which may be useful to indicate excessive stress or wear in products such as fishing lines, climbing ropes, and others.

Another possibility is to embed self-reporting microcapsules in thin films, where the most important application area would likely be packaging. While the main function of packaging is the protection of products during transportation and storage, it also has often the function to provide consumers with a sense of security. ${ }^{[109,110]}$ Thus, the use of self-reporting microcapsules could provide direct information on the integrity of packaging and the quality of the protected product, for example in the food industry. ${ }^{[111,112]}$ This type of technology may be particularly useful for tamper-evidencing packaging, and to check the integrity of the packaging of products that need to be kept sterile, such as medical supplies and medication. ${ }^{[113,114]}$

In summary, microcapsule-based mechanochromic systems are versatile, simple to implement, and stand a good chance to replace more complex existing solutions such as sensors that rely on piezoelectric transduction, changes of electrical properties, or optical fiber sensors.

\section{Conclusions and outlook}

It appears that the concept to create self-reporting materials on the basis of microcapsules that rupture upon application of excessive mechanical force and release solutions of (latent) dyes has come full circle. While the basic framework has been exploited in carbonless copy paper 
and pressure-monitoring film technologies for decades, the concept was largely forgotten in the polymer community, until it was re-discovered in the context of self-healing polymers and experienced a veritable revival. The number of reports on mechanically self-reporting polymers made by incorporation of dye-containing microcapsules is still limited, but it is clear that the approach is very useful to create materials that indicate damage or exposure to excessive stress with an optical signal. Moreover, the examples reveal that a range of different architectures and operating principles can be exploited, i.e., mechanochromic effects can be realized with different types of dyes and activation schemes. At the same time, as discussed herein, many aspects remain unexplored. On the one hand, other architectures appear useful, including double-walled capsules that can be exploited to create systems that function independent of the matrix. These architectures can be combined with a range of dyeactivation schemes that have yet to be explored in self-reporting systems and which offer characteristics, notably to achieve quantitative assessments. Most capsules are made by in-situ polymerization techniques, which lead to a relatively large diameter size. Thus alternative fabrication techniques should be of great interest to generate capsules not only with different dimensions but also with various chemical shell structure, which would provide new properties and permit the encapsulation of different core materials. All of these factors can therefore be tuned depending on the area of application or simply open new opportunities. Finally, little is known about the mechanics of capsules in polymers systematics investigations specifically focusing on the influence of capsule shell materials, the size of the capsules and the thickness toward the hosted matrix and its mode of mechanical deformation are paramount of interest for a rational design of efficient self-reporting materials.

\section{Acknowledgements}

The authors gratefully acknowledge the help of M. Karman and O. Rifaie-Graham with the design of the figures. This work was supported by the Swiss National Science Foundation 
through the National Center of Competence in Research Bio-Inspired Materials, and the Adolphe Merkle Foundation.

Received: ((will be filled in by the editorial staff))

Revised: ((will be filled in by the editorial staff)) Published online: ((will be filled in by the editorial staff)) 


\section{References}

[1] C. Weder, Mechanochromic Polymers, Springer Berlin Heidelberg, Berlin, Heidelberg, 2021.

[2] K. Imato, T. Kanehara, T. Ohishi, M. Nishihara, H. Yajima, M. Ito, A. Takahara, H. Otsuka, ACS Macro Lett. 2015, 4, 1307.

[3] G. R. Gossweiler, C. L. Brown, G. B. Hewage, E. Sapiro-Gheiler, W. J. Trautman, G. W. Welshofer, S. L. Craig, ACS Appl. Mater. Interfaces 2015, 7, 22431.

[4] D. R. T. Roberts, S. J. Holder, J. Mater. Chem. 2011, 21, 8256.

[5] Y. Liu, H. Wang, W. Zhao, M. Zhang, H. Qin, Y. Xie, Sensors 2018, 18.

[6] L. Ye, Y. Lu, Z. Su, G. Meng, Compos. Sci. Technol. 2005, 65, 1436.

[7] K. Friedrich, A. A. Almajid, Appl. Compos. Mater. 2013, 20, 107.

[8] K. Stylidis, C. Wickman, R. Söderberg, Procedia CIRP 2015, 36, 165.

[9] M. Schröder, B. Falk, R. Schmitt, Procedia CIRP 2016, 51, 116.

[10] O. Rifaie-Graham, E. A. Apebende, L. K. Bast, N. Bruns, Adv. Mater. 2018, 30, 1.

[11] D. H. Park, J. Hong, I. S. Park, C. W. Lee, J. M. Kim, Adv. Funct. Mater. 2014, 24 , 5186.

[12] J. N. Brantley, K. M. Wiggins, C. W. Bielawski, Polym. Int. 2013, 62, 2.

[13] J. Li, C. Nagamani, J. S. Moore, Acc. Chem. Res. 2015, 48, 2181.

[14] M. M. Caruso, D. A. Davis, Q. Shen, S. A. Odom, N. R. Sottos, S. R. White, J. S. Moore, Chem. Rev. 2009, 109, 5755.

[15] D. A. Davis, A. Hamilton, J. Yang, L. D. Cremar, D. Van Gough, S. L. Potisek, M. T. Ong, P. V Braun, T. J. Martínez, S. R. White, J. S. Moore, N. R. Sottos, Nature 2009, $459,68$.

[16] J. R. Hemmer, P. D. Smith, M. Van Horn, S. Alnemrat, B. P. Mason, J. R. De Alaniz, S. Osswald, J. P. Hooper, J. Polym. Sci. Part B Polym. Phys. 2014, 52, 1347.

[17] S. S. Sathe, D. Ahn, T. F. Scott, Ind. Eng. Chem. Res. 2015, 54, 4203.

[18] C. Löwe, C. Weder, Adv. Mater. 2002, 14, 1625.

[19] A. P. Esser-Kahn, S. A. Odom, N. R. Sottos, S. R. White, J. S. Moore, Macromolecules 2011, 44, 5539.

[20] J. F. Patrick, M. J. Robb, N. R. Sottos, J. S. Moore, S. R. White, Nature 2016, 540, 363.

[21] M. A. White, J. Chem. Educ. 1998, 75, 1119.

[22] S. Shojiro, US Patent 5,075,279., 1991.

[23] E. N. B. \& S. V. S. R. White, N. R. Sottos, P. H. Geubelle, J. S. Moore, M. R. Kessler, S. R. Sriram, Nature 2001, 409, 794.

[24] S. R. White, B. J. Blaiszik, S. L. B. Kramer, S. C. Olugebefola, J. S. Moore, N. R. Sottos, Am. Sci. 2011, 99, 392.

[25] B. Andrade, Z. Song, J. Li, S. C. Zimmerman, J. Cheng, J. S. Moore, K. Harris, J. S. Katz, ACS Appl. Mater. Interfaces 2015, 7, 6359.

[26] E. N. Brown, M. R. Kessler, N. R. Sottos, S. R. White, J. Microencapsul. 2003, 20, 719.

[27] H. H. Noh, J. K. Lee, Express Polym. Lett. 2013, 7, 88.

[28] Y. K. Song, K. H. Lee, D. M. Kim, C. M. Chung, Sensors Actuators, B Chem. 2016, $222,1159$.

[29] B. Di Credico, G. Griffini, M. Levi, S. Turri, ACS Appl. Mater. Interfaces 2013, 5, 6628.

[30] G. Postiglione, A. Colombo, C. Dragonetti, M. Levi, S. Turri, G. Griffini, Sensors Actuators, B Chem. 2017, 248, 35.

[31] S. A. Odom, A. C. Jackson, A. M. Prokup, S. Chayanupatkul, N. R. Sottos, S. R. White, J. S. Moore, ACS Appl. Mater. Interfaces 2011, 3, 4547.

[32] S. Vidinejevs, A. N. Aniskevich, A. Gregor, M. Sjöberg, G. Alvarez, J. Intell. Mater. Syst. Struct. 2012, 23, 1371. 
[33] M. A. White, J. Chem. Educ. 1998, 75, 1119.

[34] W. Li, C. C. Matthews, K. Yang, M. T. Odarczenko, S. R. White, N. R. Sottos, $A d v$. Mater. 2016, 28, 2189.

[35] S. Vidinejevs, O. Strekalova, A. Aniskevich, S. Gaidukov, Mech. Compos. Mater. 2013, 49, 77.

[36] E. T. A. Van Den Dungen, B. Loos, B. Klumperman, Macromol. Rapid Commun. 2010, 31,625 .

[37] A. Lavrenova, J. Farkas, C. Weder, Y. C. Simon, ACS Appl. Mater. Interfaces 2015, 7, 21828.

[38] D. Döhler, S. Rana, H. Rupp, H. Bergmann, S. Behzadi, D. Crespy, W. H. Binder, Chem. Commun. 2016, 52, 11076.

[39] J. Mei, Y. Hong, J. W. Y. Lam, A. Qin, Y. Tang, B. Z. Tang, Adv. Mater. 2014, 26, 5429.

[40] M. J. Robb, W. Li, R. C. R. Gergely, C. C. Matthews, S. R. White, N. R. Sottos, J. S. Moore, ACS Cent. Sci. 2016, 2, 598.

[41] J. Kunzelman, B. R. Crenshaw, M. Kinami, C. Weder, Macromol. Rapid Commun. 2006, 27, 1981.

[42] J. Kunzelman, B. R. Crenshaw, C. Weder, J. Mater. Chem. 2007, 17, 2989.

[43] B. R. Crenshaw, C. Weder, Chem. Mater. 2003, 15, 4717.

[44] C. Calvino, A. Guha, C. Weder, S. Schrettl, Adv. Mater. 2018, 30, 1704603.

[45] J. W. C. Pang, I. P. Bond, Compos. Part A Appl. Sci. Manuf. 2005, 36, 183.

[46] S. Kling, T. Czigány, Compos. Sci. Technol. 2014, 99, 82.

[47] M. Hu, S. Peil, Y. Xing, D. Döhler, L. Caire da Silva, W. H. Binder, M. Kappl, M. B. Bannwarth, Mater. Horizons 2018, 5, 51.

[48] D. Wu, A. C. Sedgwick, T. Gunnlaugsson, E. U. Akkaya, J. Yoon, T. D. James, Chem. Soc. Rev. 2017, 46, 7105.

[49] T. W. Bell, N. M. Hext, Chem. Soc. Rev. 2004, 33, 589.

[50] A. P. De Silva, H. Q. N. Gunaratne, T. Gunnlaugsson, A. J. M. Huxley, C. P. McCoy, J. T. Rademacher, T. E. Rice, Chem. Rev. 1997, 97, 1515.

[51] A. J. M. Huxley, M. Schroeder, H. Q. Nimal Gunaratne, A. Prasanna De Silva, Angew. Chemie - Int. Ed. 2014, 53, 3622.

[52] B. Daly, J. Ling, A. P. de Silva, Chem. Soc. Rev. 2015, 44, 4203.

[53] A. Raman, G. Augustine, N. Ayyadurai, S. Easwaramoorthi, New J. Chem. 2018, 42, 9300.

[54] T. Gunnlaugsson, A. P. Davis, M. Glynn, Chem. Commun. 2001, 2556.

[55] C. Suksai, T. Tuntulani, Top. Curr. Chem. 2005, 255, 163.

[56] C. Calvino, M. Piechowicz, S. J. Rowan, S. Schrettl, C. Weder, Chem. - A Eur. J. 2018, 24, 7369.

[57] J. Zhao, S. Ji, Y. Chen, H. Guo, P. Yang, Phys. Chem. Chem. Phys. 2012, 14, 8803.

[58] P. Majumdar, J. Zhao, J. Phys. Chem. B 2015, 119, 2384.

[59] V. S. Padalkar, S. Seki, Chem. Soc. Rev. 2016, 45, 169.

[60] M. Cai, Z. Gao, X. Zhou, X. Wang, S. Chen, Y. Zhao, Y. Qian, N. Shi, B. Mi, L. Xie, W. Huang, Phys. Chem. Chem. Phys. 2012, 14, 5289.

[61] K. Sakai, T. Ishikawa, T. Akutagawa, J. Mater. Chem. C 2013, 1, 7866.

[62] S. Tong, S. Zhao, Q. He, Q. Wang, M. X. Wang, J. Zhu, Angew. Chemie - Int. Ed. 2017, 56,6599 .

[63] L. Giordano, V. V. Shvadchak, J. A. Fauerbach, E. A. Jares-Erijman, T. M. Jovin, J. Phys. Chem. Lett. 2012, 3, 1011.

[64] P. Alreja, N. Kaur, RSC Adv. 2016, 6, 23169.

[65] L. He, B. Dong, Y. Liu, W. Lin, Chem. Soc. Rev. 2016, 45, 6449.

[66] O. A. Bozdemir, R. Guliyev, O. Buyukcakir, S. Selcuk, S. Kolemen, G. Gulseren, T. 
Nalbantoglu, H. Boyaci, E. U. Akkaya, J. Am. Chem. Soc. 2010, 132, 8029.

[67] R. Vadrucci, A. Monguzzi, F. Saenz, B. D. Wilts, Y. C. Simon, C. Weder, Adv. Mater. 2017, 29, 1 .

[68] Y. C. Simon, C. Weder, J. Mater. Chem. 2012, 22, 20817.

[69] R. R. Islangulov, J. Lott, C. Weder, F. N. Castellano, J. Am. Chem. Soc. 2007, 129, 12652.

[70] J. L. Geng, W. Li, L. P. Smaga, N. R. Sottos, J. Chan, Chem. Mater. 2018, 30, 2198.

[71] R. Dubey, T. C. Shami, K. U. Bhasker Rao, Def. Sci. J. 2009, 59, 82.

[72] Y. Ma, Y. Jiang, H. Tan, Y. Zhang, J. Gu, Polymers. 2017, 9, 24.

[73] J. P. Wang, X. P. Zhao, H. L. Guo, Q. Zheng, Langmuir 2004, 20, 10845.

[74] X. Zhu, Y. Liu, Z. Li, W. Wang, Sci. Rep. 2018, 8, 1.

[75] H. Zhang, X. Wang, Colloids Surfaces A Physicochem. Eng. Asp. 2009, 332, 129.

[76] W. Li, X. Zhu, N. Zhao, Z. Jiang, Materials. 2016, 9, 152.

[77] I. Sondi, T. H. Fedynyshyn, R. Sinta, E. Matijević, Langmuir 2000, 16, 9031.

[78] A. Kanellopoulos, P. Giannaros, D. Palmer, A. Kerr, A. Al-Tabbaa, Smart Mater. Struct. 2017, 26, 45025.

[79] E. N. Brown, N. R. Sottos, S. R. White, Exp. Mech. 2002, 42, 372.

[80] J. D. Rule, N. R. Sottos, S. R. White, Polymer. 2007, 48, 3520.

[81] Q. Li, A. K. Mishra, N. H. Kim, T. Kuila, K. T. Lau, J. H. Lee, Compos. Part B Eng. 2013, 49, 6 .

[82] S. K. Yadav, K. C. Khilar, A. K. Suresh, J. Memb. Sci. 1997, 125, 213.

[83] L. Lv, E. Schlangen, Z. Yang, F. Xing, Materials 2016, 9, 1.

[84] W. L. Chou, P. Y. Lee, C. L. Yang, W. Y. Huang, Y. S. Lin, Micromachines 2015, 6, 1249.

[85] D. Saeki, S. Sugiura, T. Kanamori, S. Sato, S. Ichikawa, Lab Chip 2010, 10, 357.

[86] P. W. Chen, R. M. Erb, A. R. Studart, Langmuir 2012, 28, 144.

[87] P. W. Chen, J. Brignoli, A. R. Studart, Polym. 2014, 55, 6837.

[88] C. L. Mou, W. Wang, Z. L. Li, X. J. Ju, R. Xie, N. N. Deng, J. Wei, Z. Liu, L. Y. Chu, Adv. Sci. 2018, 5, 1700960.

[89] H. Jin, C. L. Mangun, A. S. Griffin, J. S. Moore, N. R. Sottos, S. R. White, Adv. Mater. 2014, 26, 282.

[90] L. Yuan, A. Gu, G. Liang, Mater. Chem. Phys. 2008, 110, 417.

[91] M. M. Caruso, B. J. Blaiszik, H. Jin, S. R. Schelkopf, D. S. Stradley, N. R. Sottos, S. R. White, J. S. Moore, ACS Appl. Mater. Interfaces 2010, 2, 1195.

[92] S. Kang, M. Baginska, S. R. White, N. R. Sottos, ACS Appl. Mater. Interfaces 2015, 7, 10952.

[93] A. Jamekhorshid, S. M. Sadrameli, M. Farid, Renew. Sustain. Energy Rev. 2014, 31, 531.

[94] N. Shahabudin, R. Yahya, S. N. Gan, Macromol. Symp. 2015, 354, 305.

[95] N. Shahabudin, R. Yahya, S. N. Gan, Mater. Today Proc. 2016, 3, S88.

[96] H. Melhuish, J. Phys. Chem. 1961, 65, 229.

[97] Y. Chen, H. Lian, Y. Wei, X. He, Y. Chen, B. Wang, Q. Zeng, J. Lin, Nanoscale 2018, 10, 6734 .

[98] A. Kanellopoulos, P. Giannaros, A. Al-Tabbaa, Constr. Build. Mater. 2016, 122, 577.

[99] M. P. Neubauer, M. Poehlmann, A. Fery, Adv. Colloid Interface Sci. 2014, 207, 65.

[100] M. W. Keller, N. R. Sottos, Exp. Mech. 2006, 46, 725.

[101] G. Sun, Z. Zhang, Int. J. Pharm. 2002, 242, 307.

[102] S. a Odom, A. C. Jackson, A. M. Prokup, S. Chayanupatkul, N. R. Sottos, S. R. White, J. S. Moore, ACS Appl. Mater. Interfaces 2011, 3, 4547.

[103] M. W. Keller, S. R. White, N. R. Sottos, Adv. Funct. Mater. 2007, 17, 2399.

[104] J. Polák, J. Man, M. Petrenec, Procedia Mater. Sci. 2012, 1, 3. 
[105] Y. K. Song, B. Kim, T. H. Lee, J. C. Kim, J. H. Nam, S. M. Noh, Y. Il Park, Macromol. Rapid Commun. 2017, 38, 1600657.

[106] L. Tang, J. Whalen, G. Schutte, C. Weder, ACS Appl. Mater. Interfaces 2009, 1, 688.

[107] L. Ye, Y. Lu, Z. Su, G. Meng, Compos. Sci. Technol. 2005, 65, 1436.

[108] M. Freemantle, Chem. Eng. News 2003, 81, 10.

[109] M. G. Addbalkrim, S. R. AL-Hrezat, 2013, 5, 17.

[110] A. R. Raheem, P. Vishnu, A. M. Ahmed, Eur. J. Sci. Res. 2014, 122, 125.

[111] K. Marsh, B. Bugusu, J. Food Sci. 2007, 72, R39.

[112] G. L. Robertson, Food Packaging: Principles and Practice, CRC Press, 1998.

[113] D. A. Dean, E. R. Evans, I. H. Hall, Pharmaceutical Packaging Technology, CRC Press, 2000.

[114] N. Zadbuke, S. Shahi, B. Gulecha, A. Padalkar, M. Thube, J. Pharm. Bioallied Sci. 2013, 5, 98 . 
A) Simple release

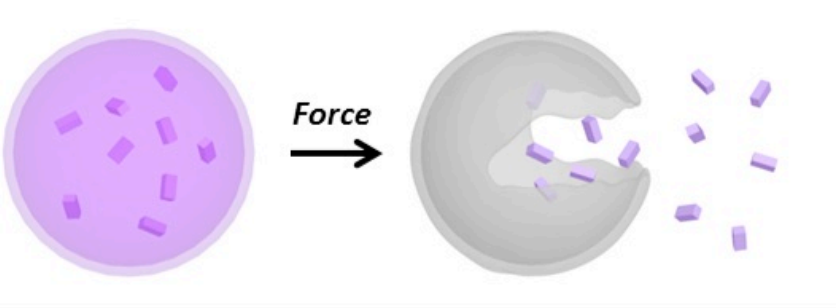

B) “Turn-on” mechanism
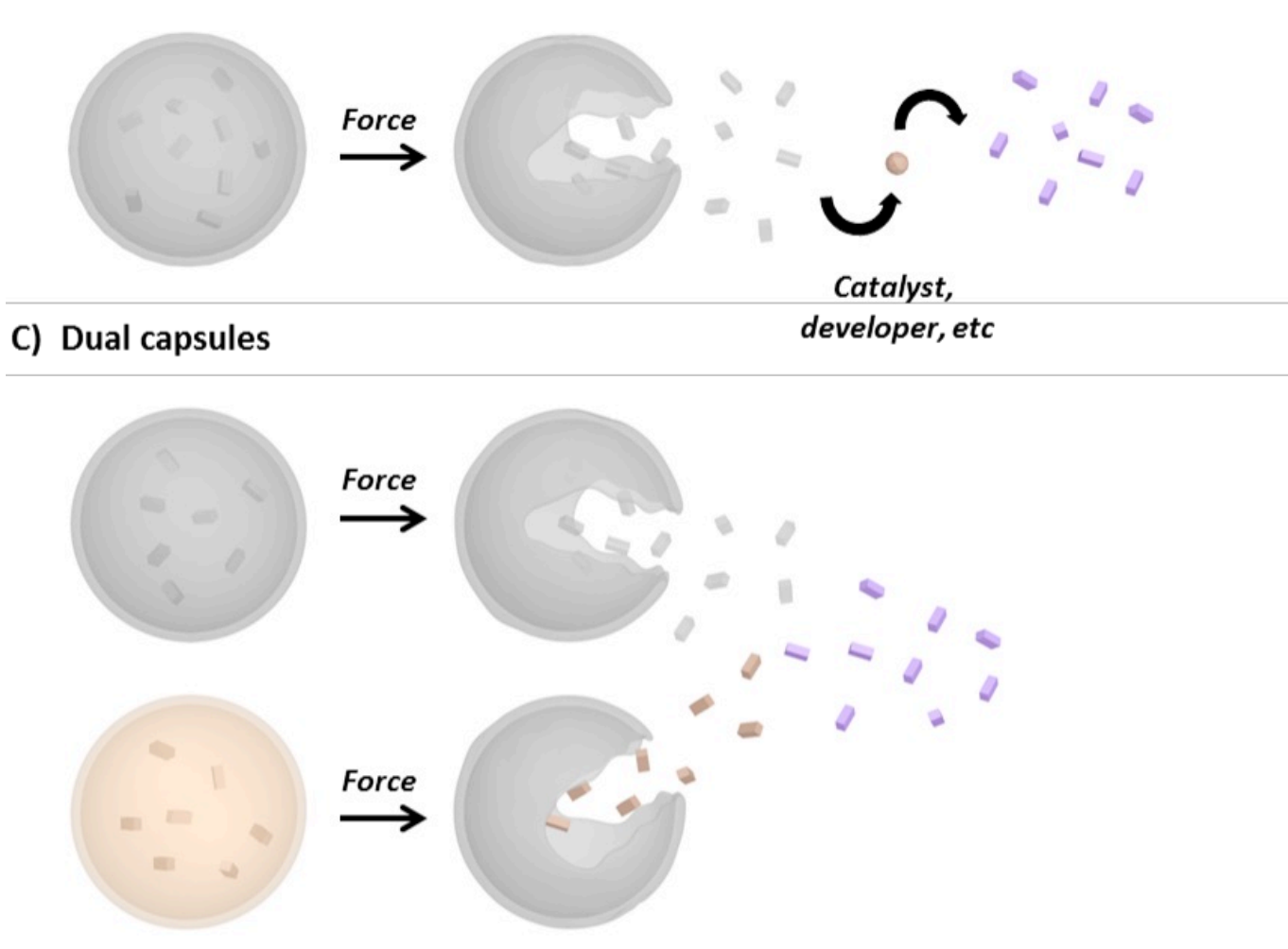

D) Aggregation-induced optical changes

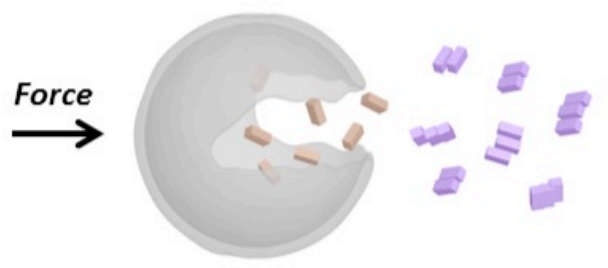

E) Other architecture - double walled system

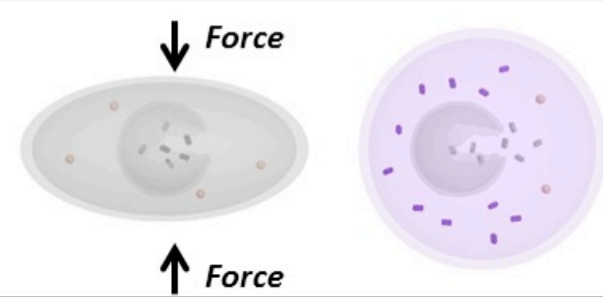

Figure 1. Schematic representation of known (A-D) and one proposed (E) operating modes for capsule-based self-reporting polymers. 
B)
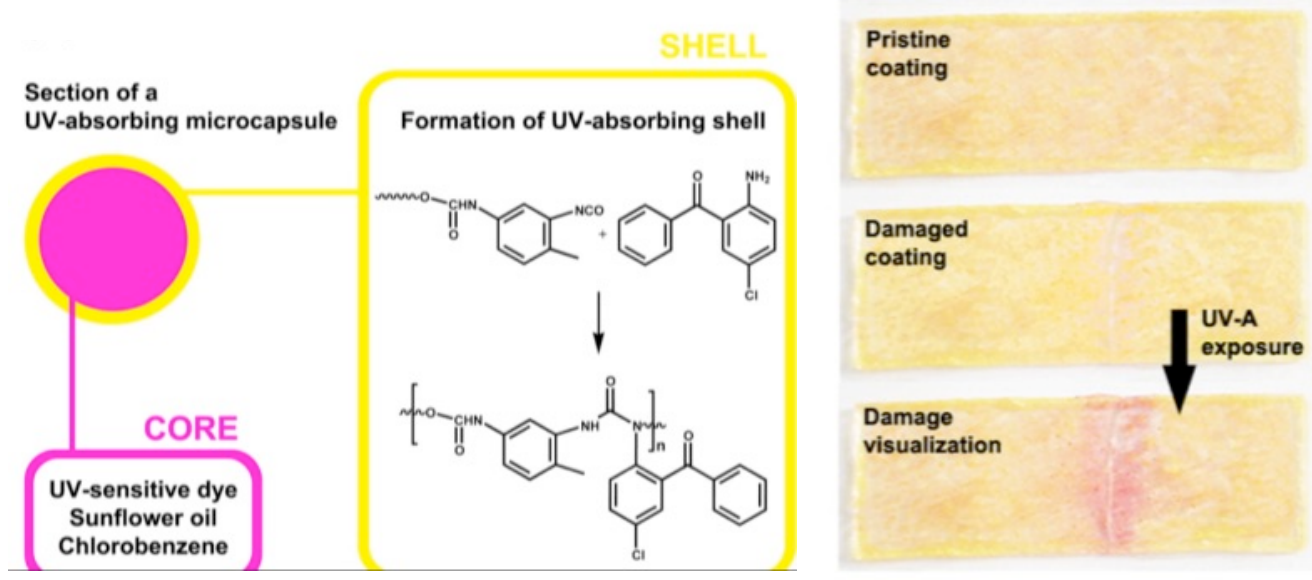

Figure 2. A) Scheme picturing the constituents of the shell and the core of the microcapsule. B) Photographs illustrating of the visual damage detection of PEGMA-based films containing these microcapsules after exposure to UV-A light. Reproduced and adapted with permission from Ref. ${ }^{[29]}$, Copyright 2013, American Chemical Society.

A)

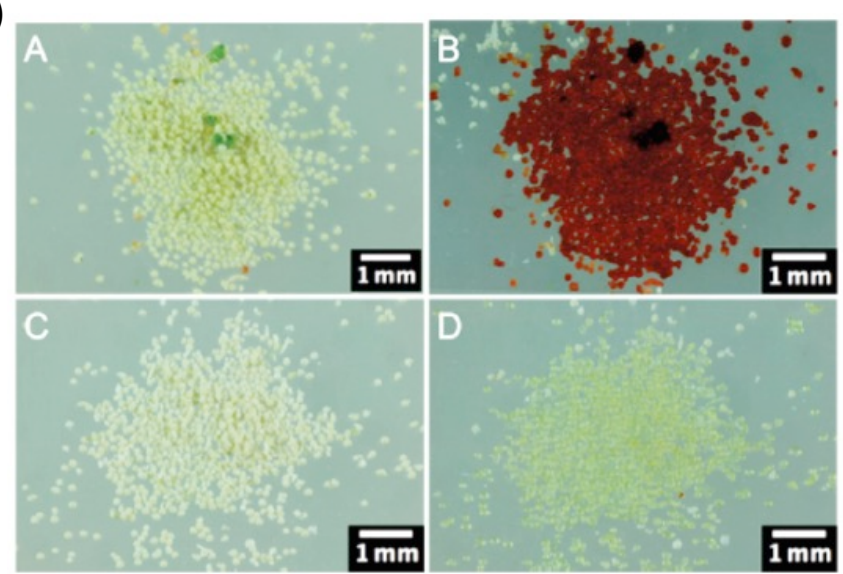

B)

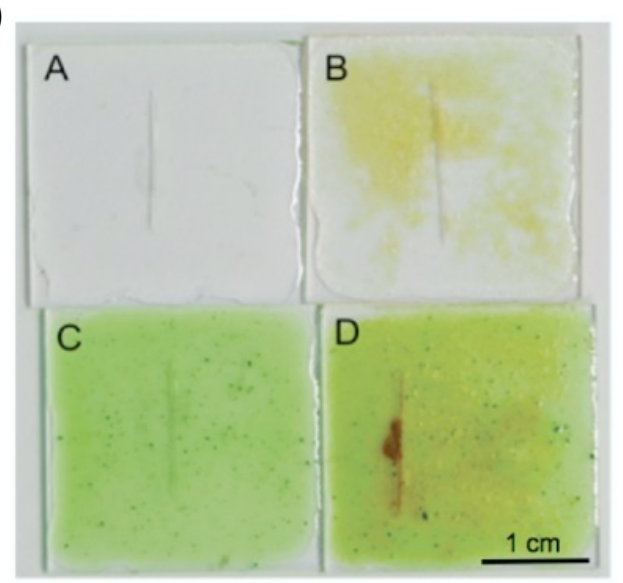

Figure 3. A) A. Photographs of microcapsules filled with COT and mixed with $5 \mathrm{wt} \%$ Grubbs-Love catalyst before rupture, B. 1 min after their breakage, C. Intact microcapsules without the catalyst, D. 1 min after their breakage. B) A. Photographs of neat poly(acrylic acid) (PAA) matrix, B. PAA containing $15 \mathrm{wt} \%$ of COT microcapsules, C. PAA mixed with $1,5 \mathrm{wt} \%$ of Grubbs-Love catalyst, D. PAA containing $15 \mathrm{wt} \%$ of COT microcapsules and 1,5 wt $\%$ of Grubbs-Love catalyst. Photographs were taken 2 min after being scratched with a razor blade. Reproduced and adapted with permission from Ref.[31], Copyright 2011, American Chemical Society. 
A)

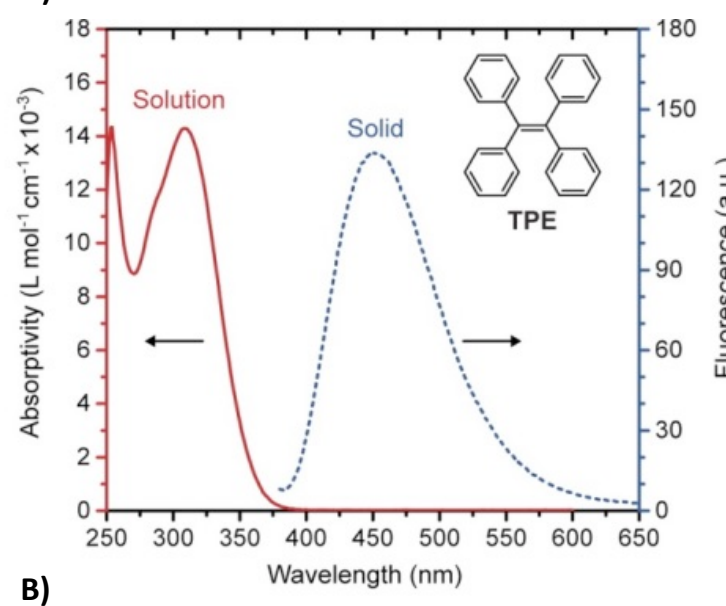

B)

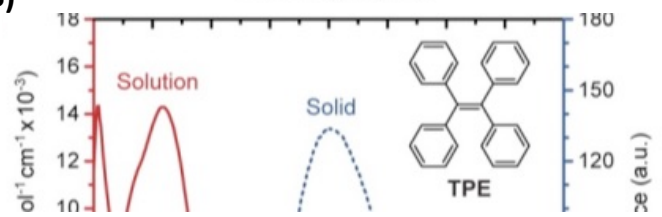

C)

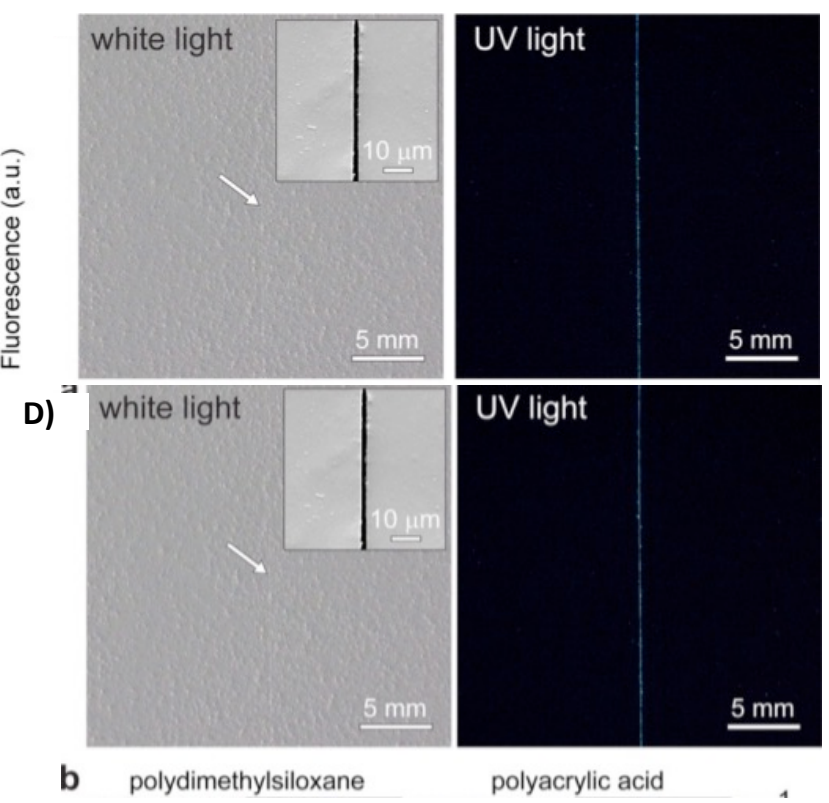

Figure 4. Damage detection in polymer composites made with microcapsules containing TPE, which displays aggregation-induced emission. A) UV-Vis absorption and fluorescence spectra of TPE in the solid state. B) Photographs of a TPE solution in hexyl acetate under UV light illumination, illustrating the AIE phenomenon upon solvent evaporation. C) Scratch damage detection in a polyurethane coating containing TPE-filled microcapsules. D) Scratch-damage detection in poly(dimethylsiloxane), poly(acrylic acid), poly(styrene), and a UV-cured epoxy. Left images show optical micrographs and right images show fluorescence intensity maps. Reproduced and adapted with permission from Ref. ${ }^{[40]}$, Copyright 2016, American Chemical Society.

A)

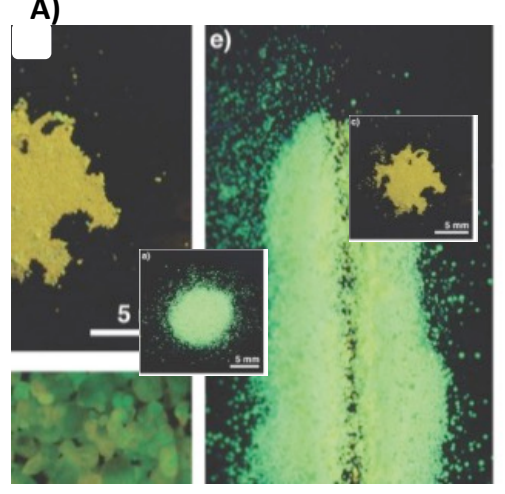

B)

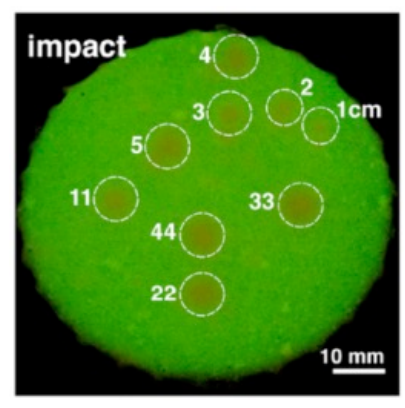

C)

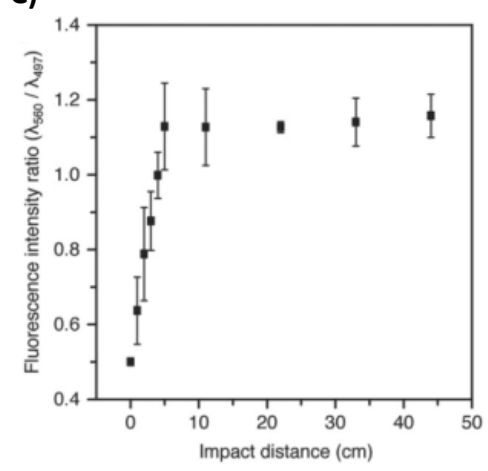

Figure 5. Damage detection in polymer composites made with microcapsules containing the excimer-forming cyano-OPV dye BCEDB. A) Plot of the ratio of the excimer:monomer ratio as function of solvent evaporation time after breaking the capsules. The insets show photographs of BCEDB-filled microcapsules before and $30 \mathrm{~min}$ after breaking them. B) Photographs recorded under UV illumination of poly(dimethylsiloxane) containing BCEDBfilled microcapsules impacted by a missile from distances between 1 and $44 \mathrm{~cm}$. C) Plot of the excimer:monomer emission intensities in the sample shown in B) recorded at 560 and $497 \mathrm{~nm}$ as function of the impact distance. Reproduced and adapted with permission from Ref. ${ }^{[44]}$,Copyright 2018, Jon Wiley \& Sons. 
A)

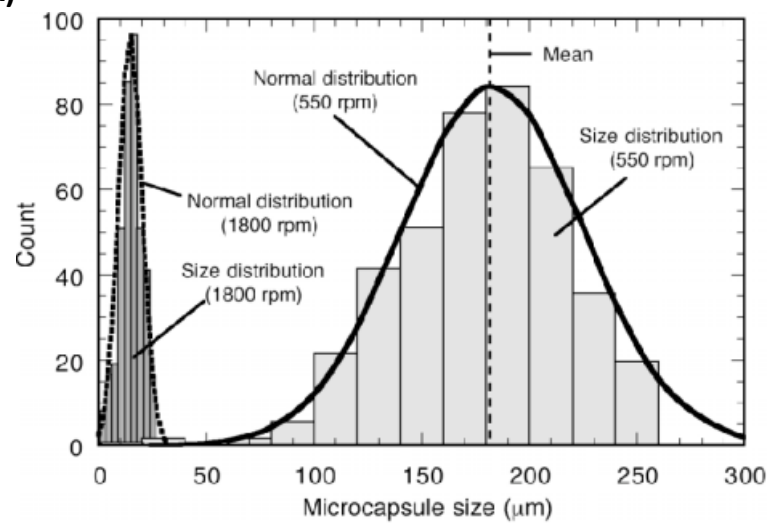

B)

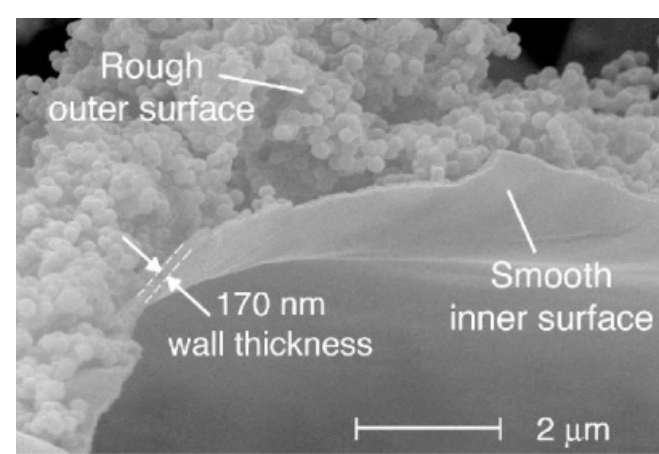

Figure 6. A) Plot showing the influence of the agitation rate in the microcapsules size distribution. B) SEM images of ruptured microcapsules composed of thin shell with smooth inner surface and a rough outer surface made of UF nanoparticles attached on the shell. Reproduced and adapted with permission from Ref. ${ }^{[26]}$, Copyright 2003, Taylor \& Francis. 


\begin{tabular}{|c|c|c|c|}
\hline $\begin{array}{l}\text { Microencapsulation } \\
\text { methods }\end{array}$ & Shell materials & Core & Applications \\
\hline \multicolumn{4}{|l|}{ Chemical methods } \\
\hline $\begin{array}{c}\text { Suspension } \\
\text { polymerization }\end{array}$ & Poly(styrene) & PCM & Textile \\
\hline Emulsion polymerization & Poly(alkyl acrylate)s & Insulin & Pharmaceutic \\
\hline Dispersion & $\begin{array}{c}\text { Poly(2-hydroxyethyl-co-glycidyl } \\
\text { methacrylate), } \\
\text { Poly (N-vinyl } \alpha \text {-phenylalanine) }\end{array}$ & $\begin{array}{l}\text { Ferrofluid } \\
\text { Fluorescein } \\
\text { isothiocyanate }\end{array}$ & Bio-applications \\
\hline Interfacial & $\begin{array}{l}\text { Polyurea, } \\
\text { Polyamide, } \\
\text { Polyurethane, } \\
\text { Polyester }\end{array}$ & $\begin{array}{l}\text { Insecticides, catalysts } \\
\text { Oils, } \\
\text { Insecticides, } \\
\text { Protein }\end{array}$ & $\begin{array}{l}\text { Crop protection, } \\
\text { catalysis, } \\
\text { Pharmaceutics }\end{array}$ \\
\hline \multicolumn{4}{|l|}{$\begin{array}{l}\text { Physicochemical } \\
\text { methods }\end{array}$} \\
\hline $\begin{array}{l}\text { Coacervation and phase } \\
\text { separation }\end{array}$ & $\begin{array}{l}\text { Protein, Polysaccharides, ethyl } \\
\text { cellulose, gelatin, proteins, } \\
\text { polysaccharide }\end{array}$ & $\begin{array}{l}\text { Drugs, } \\
\text { Flavors, essential oils }\end{array}$ & $\begin{array}{l}\text { Pharmaceutic, } \\
\text { Food industry }\end{array}$ \\
\hline Sol-gel encapsulation & Silica & $\begin{array}{l}\text { Organic dyes } \\
\text { Fragrance, aroma }\end{array}$ & $\begin{array}{l}\text { Textile, } \\
\text { Cosmetic, food }\end{array}$ \\
\hline $\begin{array}{l}\text { Supercritical } \mathrm{CO}_{2} \text { assisted } \\
\text { microencapsulation }\end{array}$ & $\begin{array}{c}\text { PLA, cyclodextran, Poly(ethylene } \\
\text { glycol), Phospholipids, } \\
\text { cholesterol }\end{array}$ & Drugs & Pharmaceutics \\
\hline Layer-by-layer & Polyelectrolyte (dextran) & $\begin{array}{l}\text { Drugs, polymer, } \\
\text { enzymes, DNA, } \\
\text { proteins }\end{array}$ & Pharmaceutics \\
\hline Ionotropic gelation & $\begin{array}{l}\text { Calcium alginate } \\
\text { Carboxymethyl guar gum }\end{array}$ & Glipizide, insulin & $\begin{array}{l}\text { Pharmaceutics, } \\
\text { food industry }\end{array}$ \\
\hline \multicolumn{4}{|l|}{$\begin{array}{l}\text { Physical mechanical } \\
\text { methods }\end{array}$} \\
\hline Solvent evaporation & $\begin{array}{l}\text { Poly(lactic acid), poly(lactic-co- } \\
\text { glycolic acid) }\end{array}$ & $\begin{array}{l}\text { Drugs, peptides, } \\
\text { proteins, vaccines }\end{array}$ & $\begin{array}{l}\text { Pharmaceutics, drug } \\
\text { delivery }\end{array}$ \\
\hline $\begin{array}{l}\text { Air suspension coating or } \\
\text { Fluid bed coating }\end{array}$ & Gelatin, carbohydrates, lipids & Food ingredients & Food industry \\
\hline Spray-drying & $\begin{array}{c}\text { Fatty alcohol, fatty acid } \\
\text { Galtin, gum arabic, maltodextrin, } \\
\text { alginate }\end{array}$ & $\begin{array}{l}\text { Drugs, enzymes } \\
\text { Flavors, lipid, proteins, } \\
\text { cellulose }\end{array}$ & $\begin{array}{l}\text { Pharmaceutics, } \\
\text { Food industry }\end{array}$ \\
\hline Centrifugal extrusion & $\begin{array}{l}\text { Gelatin, sodium alginate, gum } \\
\text { arabic cellulose derivatives, PEG }\end{array}$ & Flavor oils & Food industry \\
\hline Extrusion & $\begin{array}{l}\text { Carbonhydrate (starch, sucros } \\
\text { maltodextrins) }\end{array}$ & Flavor, volatiles & Food industry \\
\hline $\begin{array}{l}\text { Electrostatic } \\
\text { encapsulation }\end{array}$ & $\begin{array}{c}\mathrm{Xxx} \\
\text { Sodium alginate }\end{array}$ & $\begin{array}{l}\text { Solid (Acrylic powder) } \\
\text { Liquid (living cell, } \\
\text { enzymes) } \\
\text { Gas }\end{array}$ & Bio-applications \\
\hline Spinning disk & Paraffin & solid & Food industry \\
\hline
\end{tabular}

Table 1. Overview of different microencapsulation methods with typical shell materials, encapsulated cores and applications. Adapted from Ref ${ }^{[71]}$. 


\title{
TOC entry:
}

The incorporation of dye-containing microcapsules is an attractive approach to create self-reporting polymers that indicate damage or exposure to excessive stress with an optical signal. Based on a selection of recent studies, this concept article presents different architectures and operating principles that illustrate the scope, potential, and current limitations of the concept.

Keyword: Microcapsules, mechanochromic, self-reporting polymers, damage sensing

\author{
C. Calvino, C. Weder*
}

Title: Microcapsule-containing Self-Reporting Polymers

ToC figure: $(($ Please choose one size: $55 \mathrm{~mm}$ broad $\times 50 \mathrm{~mm}$ high or $110 \mathrm{~mm}$ broad $\times 20$ $\mathrm{mm}$ high. Please do not use any other dimensions))

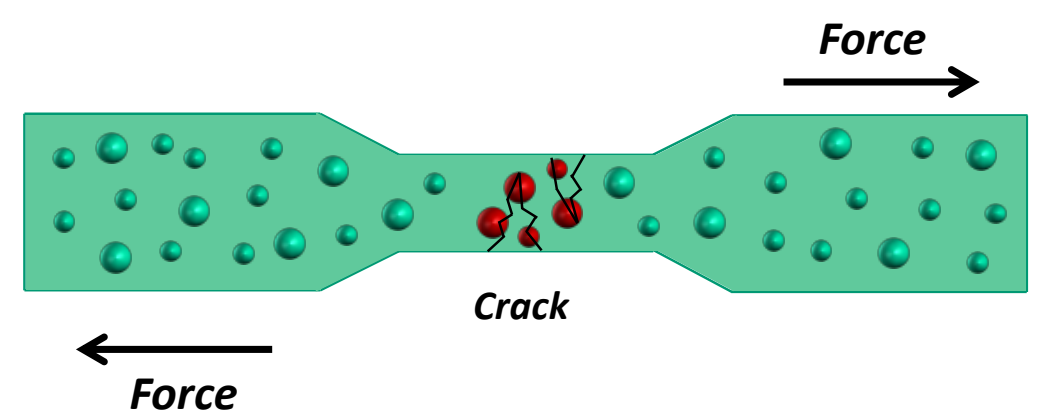

